Thorax (1975), 30, 497.

\title{
The lungs in lymphangiomyomatosis and in tuberous sclerosis
}

\author{
P. G. I. S T O VI N, L.C.LU M, C. D . R . F L O W E R, \\ C. S. D A R K E, and M. B E E L E Y \\ Papworth Hospital, Papworth Everard, Cambs CB3 8RE \\ and North General Hospital, Sheffield S5 7 AN
}

\begin{abstract}
Stovin, P. G. I., Lum, L. C., Flower, C. D. R., Darke, C. S., and Beeley, M. (1975). Thorax, 30, 497-509. The lungs in lymphangiomyomatosis and in tuberous sclerosis. Two cases of pulmonary lymphangiomyomatosis (PL) are described and 33 other cases from the literature are reviewed. These are compared with one case of tuberous sclerosis with pulmonary involvement (PTS) and 32 other cases from the literature. There are no differences in lung function between these two conditions, both of which show airways obstruction associated with diffuse radiological lung changes. There are, however, both clinical and radiological differences and also differences in the distribution of the lesions and the histological location of the excessive smooth muscle; these indicate that PL and PTS are probably different entities and not polar forms of one condition. Finally, the strictly female incidence of PL suggests a sex-linked disorder, and it is postulated that this may be related to congenital pulmonary lymphangiectasis.
\end{abstract}

In 1968 Frack, Simon, and Dawson introduced the term 'the lymphangiomyomatosis syndrome' to denote the combination of symptoms and pathological changes related to a multifocal hamartomatosis of lymphatic ducts and nodes with frequent involvement of the lungs and thoracic duct.

Largely because renal angiolipoleiomyomatous hamartomata were reported to be present with pulmonary lymphangiomyomatosis (PL) in the cases of Vadas, Pare, and Thurlbeck (1967), of Pielsticker, Kunze, and Stern (1972), of Monteforte and Kohnen (1974), and of Silverstein, Ellis, Wolff, and Jaretzki (1974) it has been suggested that PL is a forme fruste of tuberous sclerosis with pulmonary involvement (PTS).

Because PL and PTS are uncommon conditions and their relationship is obscure we report two cases of PL and one case of PTS studied clinically and histopathologically.

\section{CASE REPORTS}

CASE 1 WAD was born in 1940. There was no family history of epilepsy, mental deficiency or neonatal death. She was a physiotherapist and was fit until an unexplained haemoptysis in 1965. In 1966 she had her first spontaneous pneumo- thorax. Further bilateral pneumothoraces occurred in 1967. At that time her chest radiograph showed normal lungs. Bilateral pleurectomies and a lung biopsy were performed by $\mathrm{Mr}$. B. B. Milstein. At operation scattered bullae ranging in size from $2 \mathrm{~mm}$ to $2 \mathrm{~cm}$ were seen in all parts of the lungs. Anomalous pulmonary venous drainage from the upper lobe and a central defect in the right diaphragm were noted.

The lung biopsy showed dilated lymphatics with no discernible muscle in their walls (Fig. 1).

For the next two years she had occasional menstrual haemoptyses. Her chest radiograph showed no change. From 1970 she developed a productive cough and disabling dyspnoea, and her forced vital capacity (FVC) of 1 litre and forced expired volume in one second $\left(\mathrm{FEV}_{1}\right)$ of 0.9 litre were half the values obtained one year earlier. Lung function studies are shown in Table I. In October 1970, a large air cyst was noted in the right lung (Fig. 2) and an attempt was made to close it using tube suction. She died in June 1971 of intractable respiratory failure. Over the last three years of her life the patient had a lymphopenia with a fluctuating eosinophilia and had ceased taking a contraceptive pill. $\alpha$ and $\gamma$ globulins were normal. At no time were any septal lines seen on the chest radiographs. 


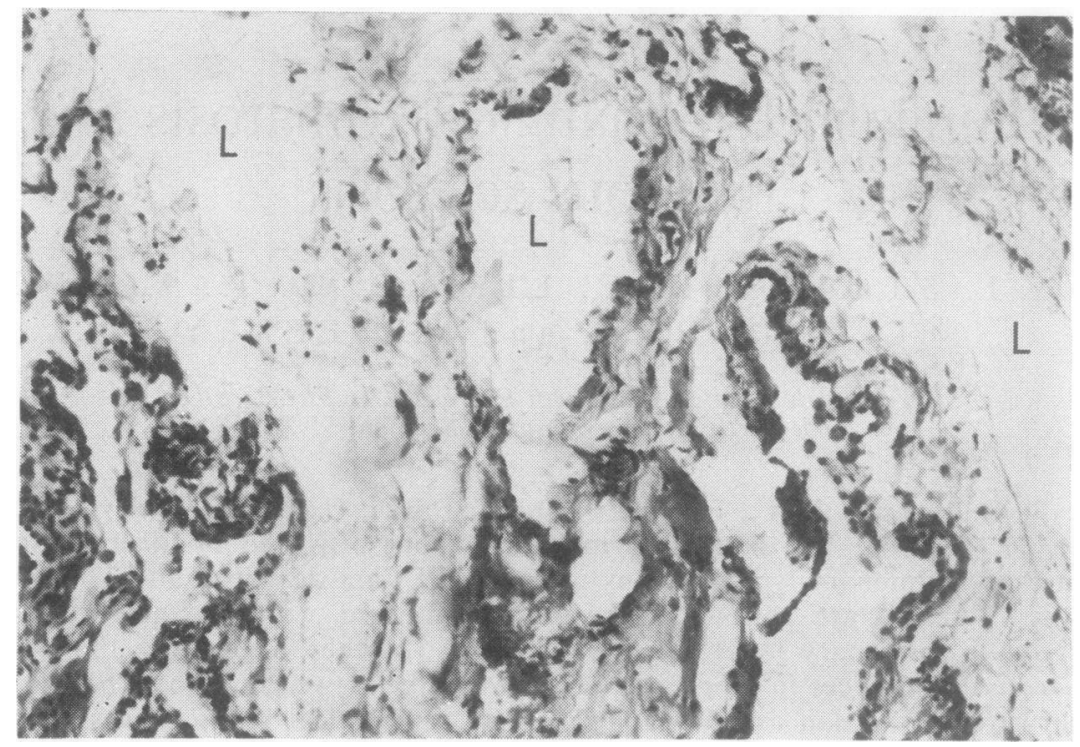

FIG. 1. Case 1. Lung biopsy. Dilated lymphatics $(L)$ in lobular septa. Intraalveolar exudate clusters (Haematoxylin and eosin $\times 122$ ).

T A B L E I

LUNG FUNCTION STUDIES

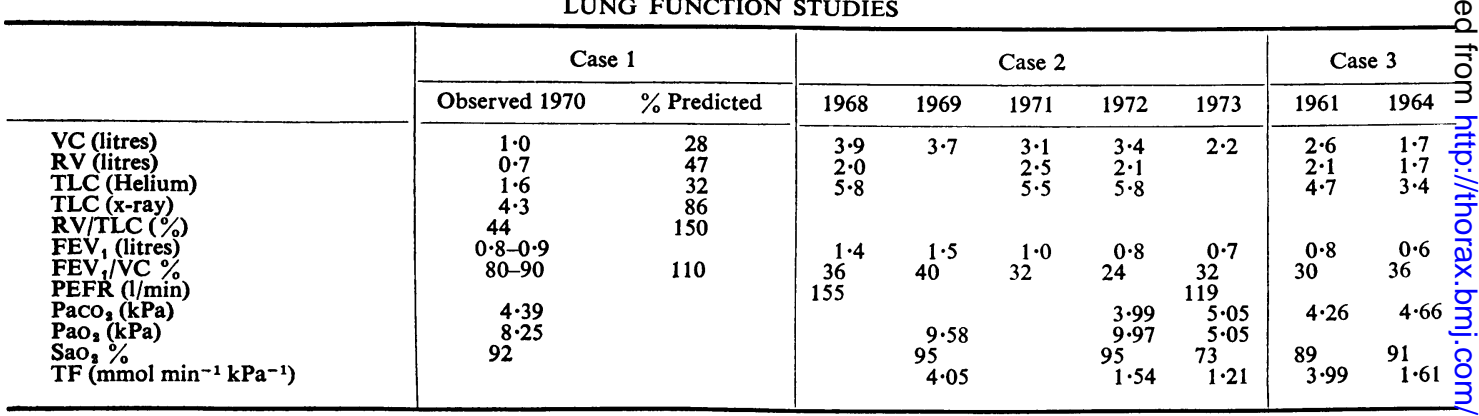

At necropsy there were $3 \mathrm{~mm}$ diameter anomalous pulmonary veins from each upper lobe; the other pulmonary veins were normal. Other congenital defects present included bilateral duplication of the lateral venous sinuses within the skull, fenestrations of the right diaphragm, and a left-sided diverticulum of the cervix uteri.

The pleural cavities were obliterated. The lungs were dry and apparently emphysematous in the upper lobes with a little oedema in the lower lobes. The lungs were fixed by formalin and later by formol-zenker continuous perfusion until they were hard. Well-defined, irregularly shaped, cystic spaces were present on serial slicing of the lungs. There was normal lung between the cysts. In the posterior angle of the right middle lobe was a large deeply situated bulla. The cysts were larger and more frequent in the upper than the lowero lobes and in some areas lay alongside bronchi. N

Around the inferior vena cava and the right common iliac vessels was a $10 \times 5 \mathrm{~cm}$ pale grey ${ }^{N}$ yellow spongy mass which exuded opalescentê fluid on section. There was a chain of calcifiedo mesenteric lymph nodes extending from theo region of the resected appendix. The paratracheato and paraoesophageal nodes were moderately en $\stackrel{?}{?}$ larged as in patients dying with respiratory infection.

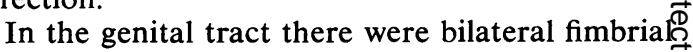
cysts, a left broad ligament fibromyoma, and a lef $\mathbb{Q}$ cornual adenomatous polyp.

The remainder of the necropsy including the brain was unremarkable. 


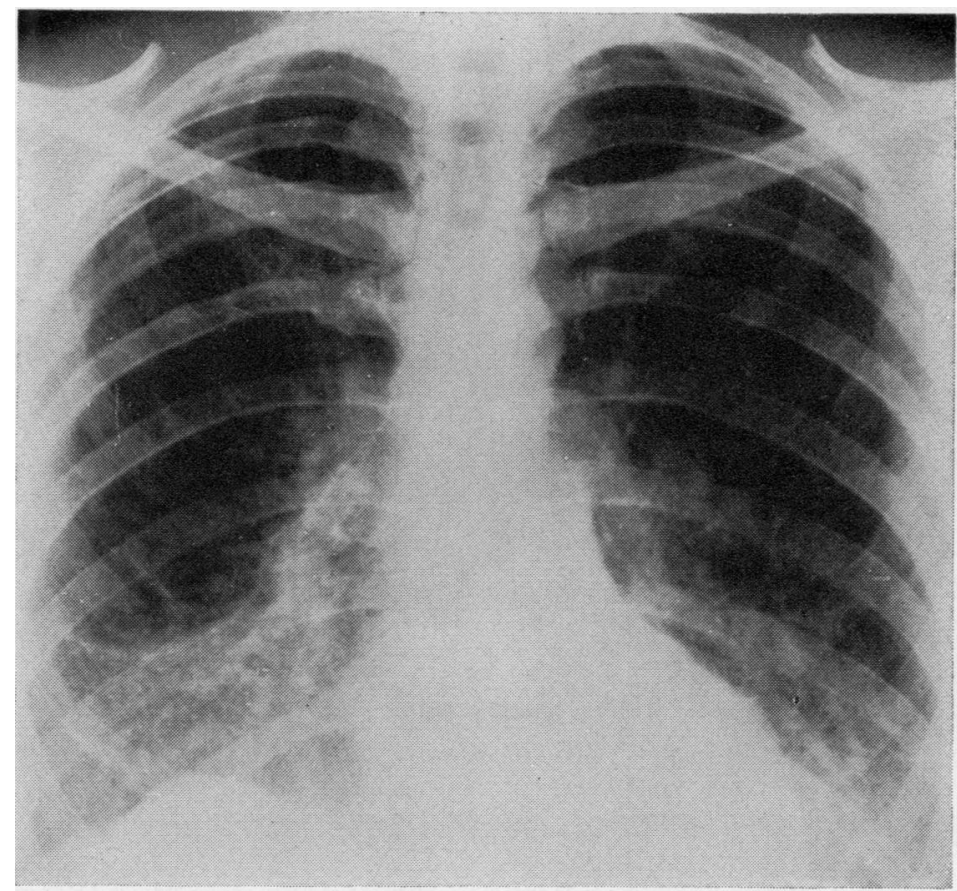

FIG. 2. Case 1. Reticular shadowing of both lower lobes and expanding air cyst in right middle zone.

Microscopically the grossly dilated spaces alongside the bronchi and arteries (Fig. 3) were devoid of cellular or proteinaceous content and were lined by thin flattened endothelium or occasionally by more swollen cuboidal cells. The walls of many of these cysts contained smooth muscle cells. Several of these cysts opened into alveoli but from their position and also because they communicated directly with abnormal lymph nodes, the cysts could only be grossly abnormal lymphatics. The large middle lobe cyst had a wall similar to these lymphatic cysts.

Lymph nodes in the lung were composed largely of multiple channels with masses of smooth muscle cells in the interstitium between the channels. Similar angioleiomyomatous lymph nodes were present at the hila of the lungs, beside the oesophagus, and in a piece of intercostal tissue; these lymph nodes contained a little carbon pigment. The same angioleiomyomatous morphology was seen in the lower abdominal tumour (Fig. 4). A small lymph node beside the thyroid was normal, as was the spleen.

The broad ligament tumour was confirmed microscopically as a leiomyoma. Microscopically the other organs were normal.
CASE 2 PL, a welfare officer with two healthy children presented with pulmonary symptoms in 1968 when she was 33 years old. She had previously been entirely well and there was no personal or family history of epilepsy or mental abnormality. For three and a half years she had suffered from exertional dyspnoea and occasional 'tight burning sensations' in the right upper chest and retrosternally. She smoked 15 cigarettes daily and had taken a contraceptive pill for five years. Physical examination revealed no abnormalities. The chest radiograph was normal as were the blood picture and sedimentation rate. Pulmonary function tests were performed and are shown in Table I.

During the next year her dyspnoea worsened and she developed a slight cough productive of a little clear sputum. Chest radiographs then showed mottling in the lower zones with small fluffy shadows. Small doses of prednisolone were tried for three months but no improvement occurred.

In 1972 she suffered a small haemoptysis and was more dyspnoeic. A chest radiograph showed a right pleural effusion with elevated diaphragm. Centrifugation of the milky pleural fluid showed 


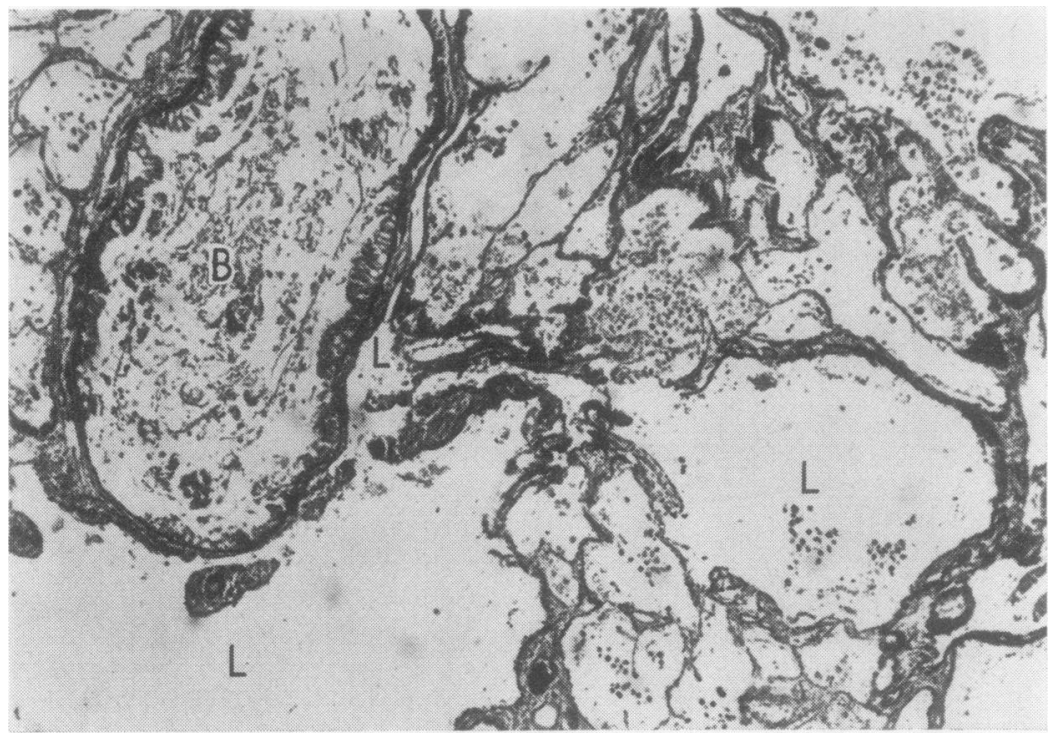

FIG. 3. Case 1. Bronchus $(B)$ with dilated lymphatics $(L)$ in the adventitia opening inferiorly and to the right into large cysts. Large amount of smooth muscle present about lymphatics, especially in centre of picture at junction of cysts $(H$ and $E \times 39)$.

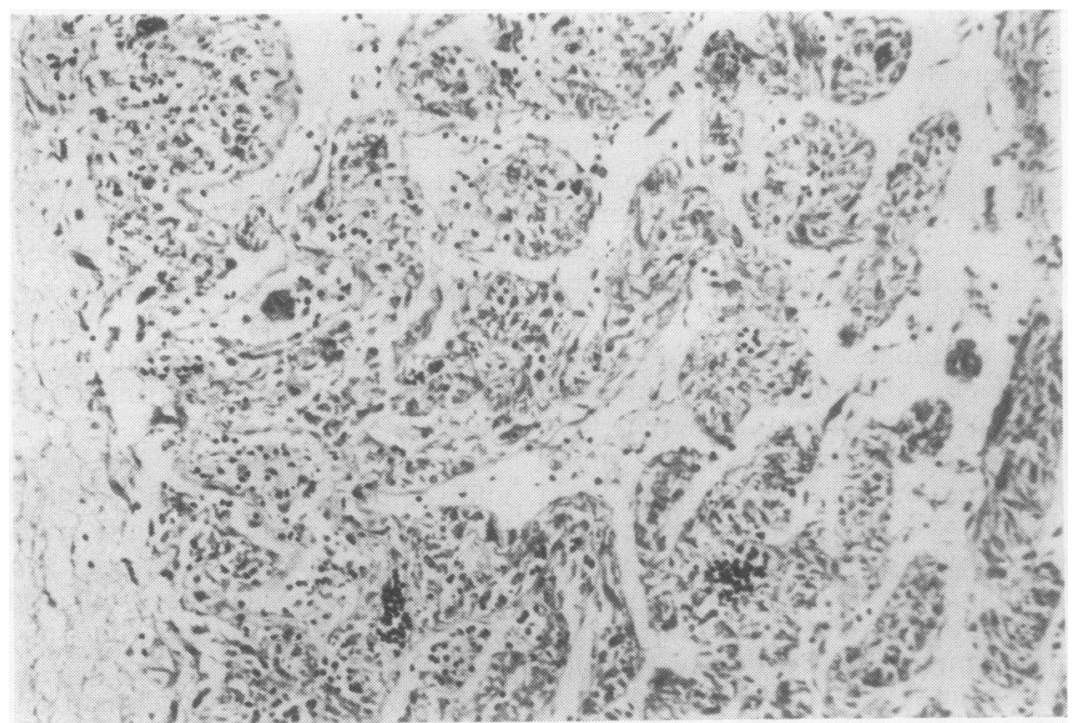

FIG. 4. Case 1. Abdominal lymphangiomyoma. Irregular trabeculae of smooth muscle cells forming the walls to sinusoids. The fluid filling the sinusoids is almost free of cells and protein. The capsule is on the left (Lissamine red $\times 122$ ). 
chylomicra on the surface and it contained $890 \mathrm{mg} / \mathrm{dl}$ triglycerides and $7 \mathrm{~g} / \mathrm{dl}$ of protein, confirming that the effusion was chylous.

Thoracotomy was performed and biopsies were taken from all three lobes of the right lung. The lung surface was noted to be covered with $3 \mathrm{~mm}$ cysts; the hilum and phrenic nerve were apparently normal. The chylothorax did not recur, but the chest radiograph showed a few septal lines (Fig. 5). Several weeks later she began to expectorate chyle and this continued until her death in November 1973.

Investigations Blood urea, serum electrolytes, proteins including electrophoresis, calcium, phos- phate, and alkaline phosphatase were each normal Latex RA and antinuclear factor tests were negative. The erythrocyte sedimentation rate was never raised. Serum IgG, IgM, and IgA were respectively 1220,117 , and $85 \mathrm{mg} / \mathrm{dl}$. Antibodies to mitochondria were not detected, but antibodies to basement membrane were demonstrable. Barium meal was normal.

Histology Lung biopsy showed muscular periarterial lymphatics (Fig. 6) together with smooth muscle bundles in the pleura and walls of the small bronchi. Clefts within these smooth muscle bundles were devoid of blood cells, indicating a lymphatic origin. There were no accumulations

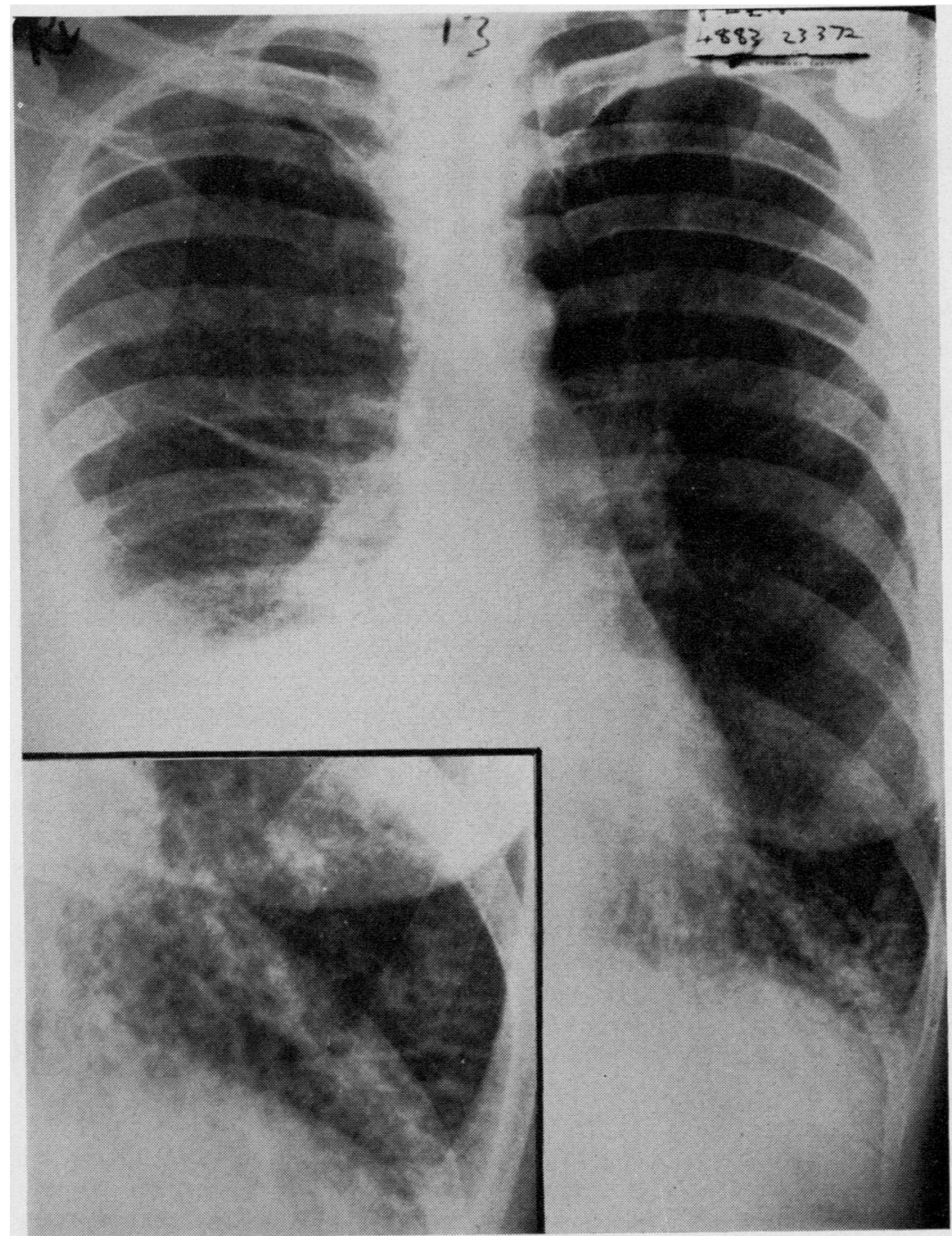

FIG. 5. Case 2. Fine reticulonodular marking throughout lungs with right basal effusion and left basal septal lines; insert at higher magnification. 


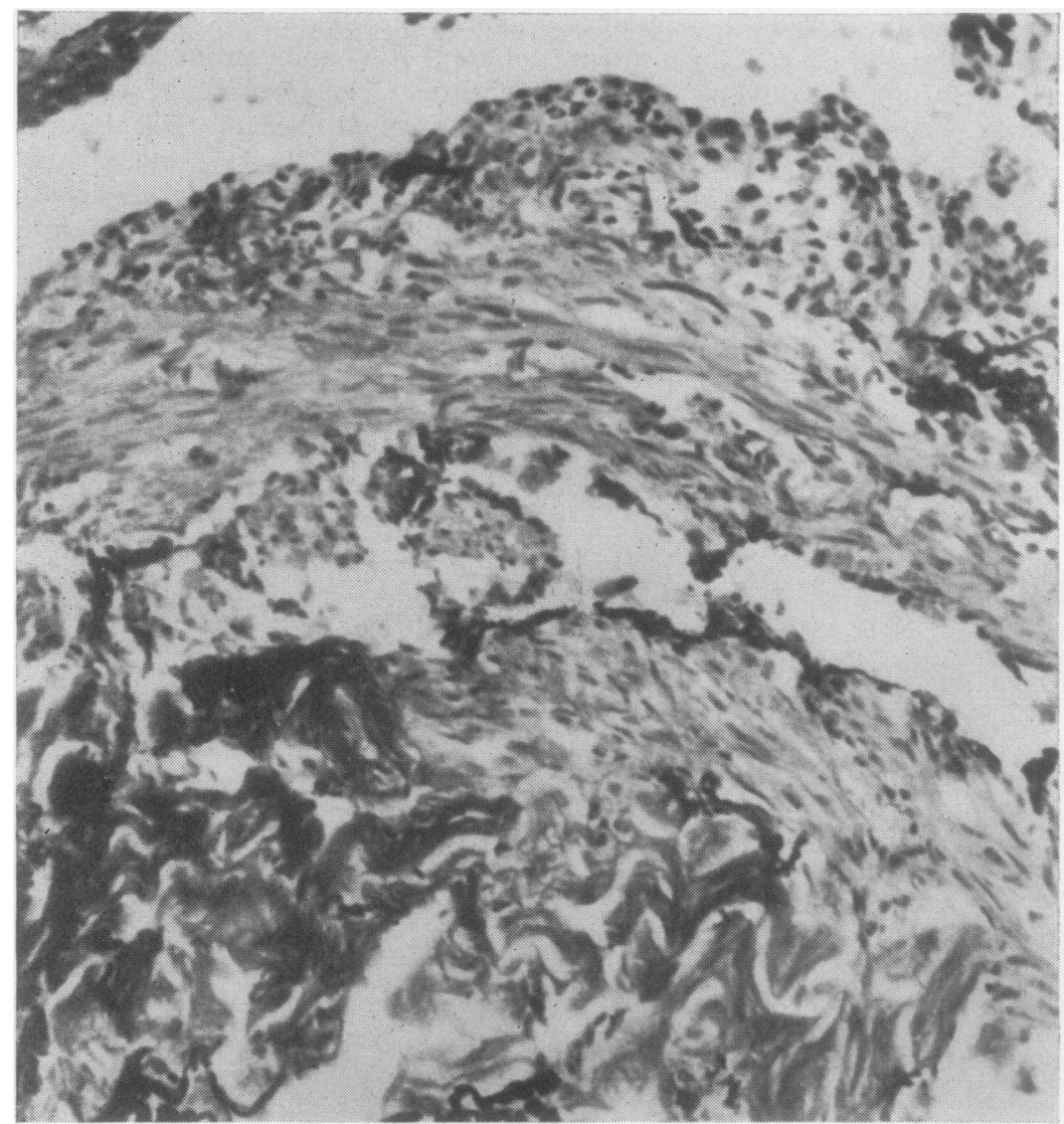

FIG. 6. Case 2. Lung biopsy. Smooth muscle in thick wall of lymphatic seen across centre of picture (Elastic van Gieson $\times 320)$.

of foamy macrophages or lipid granulomata in the dilated alveoli or respiratory bronchioles. There was one focus of siderophages in the alveoli.

Necropsy Dr. L. Henry confirmed the diagnosis of lymphangiomyomatosis of the lungs and lymph nodes and there was a retroperitoneal lymphangiomyoma adjacent to the right ureter together with chylous serous effusions. Lipid-containing macrophages were present in the alveoli.

CASE 3 GB, a mentally defective woman, whose father had died in a mental hospital, had been institutionalized since the age of 26 and was said to have suffered from rheumatic fever when 10 years old. She was under pulmonary scrutiny for her last three years. At that time she was noted to have subungual fibromata, peau chagrinée of the lumbar region, and angiomata over the nose; radiographs demonstrated cystic changes in the terminal phalanges with indentations of their lateral aspects, calcification over the left cere $\frac{0}{3}$ bellar hemisphere and in the region of the ventricles, patchy sclerosis of the lumbar vertebrae, and a nodular reticular pattern in the lowe parts of both lungs. Because of these features a. diagnosis of tuberous sclerosis was made although she had never suffered from epilepsy. Apart from slight dyspnoea of effort there were no complaints referable to the respiratory system.

Examination of the chest showed slightly< diminished breath sounds at the bases; there was? no finger clubbing. Signs of mild mitral stenosise were present. She died at the age of 59 years in congestive cardiac failure having shown generato deterioration, moderate increasing dyspnoea of effort, and a few crepitations at the lung bases. $\frac{O}{\mathbb{D}}$ Radiology Serial chest radiographs showed noㅇ changes in the appearance of the reticular nodulat shadowing of the lung fields during the three-yearo 
period of survey although slight increasing prominence of the main pulmonary artery was observed.

Physiology Pulmonary function tests were undertaken at the age of 56 and repeated three years later, five months before death. The results are shown in Table $\mathrm{I}$.

Necropsy (Dr. A. J. N. Warrack). The cutaneous, renal, and cerebral lesions of tuberous sclerosis were confirmed. The lungs were diffusely cystic with a cobblestone pleural surface. The right lung weighed $400 \mathrm{~g}$ and there were bilateral straw-coloured pleural effusions. There was typical old rheumatic stenosis of the mitral valve and slight thickening of the aortic leaves with hypertrophy of the right ventricle of the heart $(300 \mathrm{~g})$. There were numerous fibromyomata in the uterus. The other organs showed congestive changes only.

Microscopically the lungs showed a fairly uniform picture of small alveolar cysts up to $5 \mathrm{~mm}$ diameter. Most of these cysts had scattered in their walls lenticular masses of smooth muscle with central blood-filled capillaries (Fig. 7). Similar bundles of smooth muscle were seen in the alveoli immediately deep to the pleura. Larger masses of smooth muscle were present deeper in the lung, sometimes associated with small bronchi and sometimes projecting into the alveoli and cysts. All of these larger masses had central blood vessels, usually with only partially formed elastic lamellae. Focal leiomyomata were present in the elastic and larger muscular pulmonary arteries (Fig. 8). Smooth muscle bundles were present in the walls of larger subsegmental bronchi, related to bronchial blood vessels rather than to lymphatics. There was much haemosiderin in frequent intra-alveolar and interstitial macrophages. A few of the pulmonary vein branches showed a patchy intimal fibrosis, but this did not appear to be sufficiently frequent or severe to indicate that the massive haemosiderosis was due to a major degree of venous hypertension. The general picture was more indicative of vascular leaks from the poorly formed blood vessels in the angioleiomyomatous tissue.

The lymphatics in some parts of the lung were dilated and nearly always without hypertrophied muscle. In some of the hilar lymph nodes there was smooth muscle in the capsule and about blood vessels in the substance of the cortex of the node (Fig. 9).

Typical angioleiomyomata up to $1.5 \mathrm{~cm}$ diameter were present in the kidneys, and there was a small leiomyomatous plaque attached to the surface of one ovary.

\section{DISCUSSION}

CLINICAL In 1971 Miller, Cornog, and Sullivan reviewed 27 published cases of lymphangiomyomatosis. We would not accept the second case of Wuketich (1967) as a case of PL as he describes

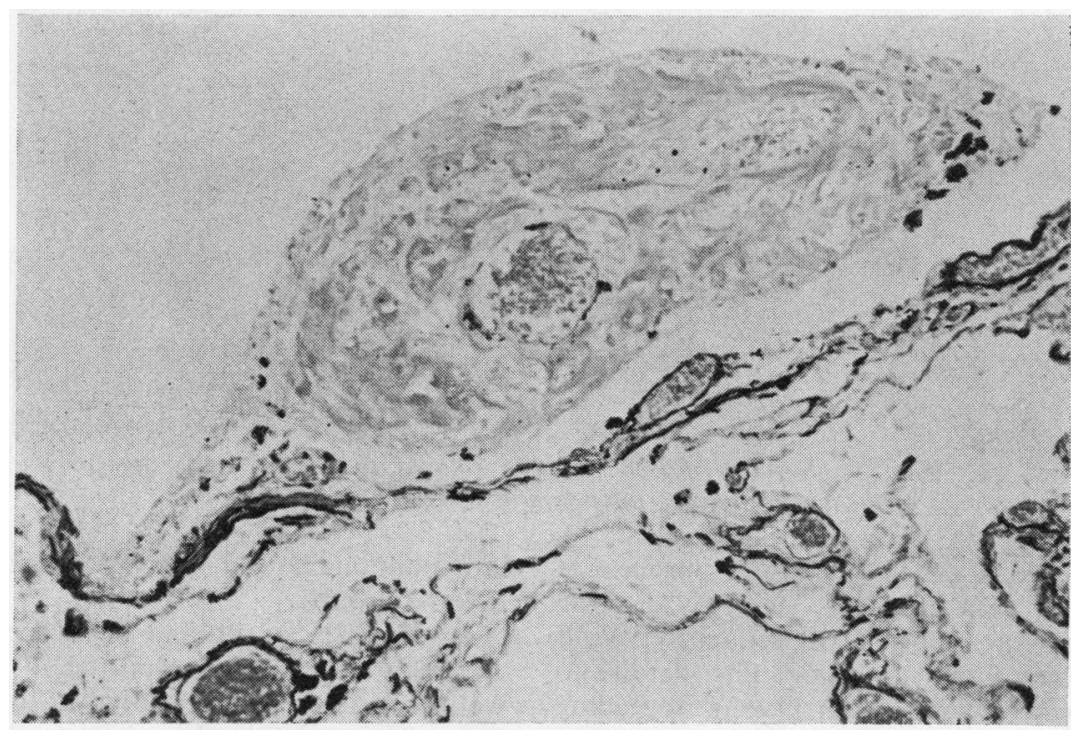

FIG. 7. Case 3. Irregular smooth muscle proliferation about blood vessels with projection into alveolar air cyst in upper half of picture (EVG $\times 122)$. 
FIG. 8. Case 3. Three smooth muscle tumours in wall of elastic pulmonary artery $(E V G \times 150)$.

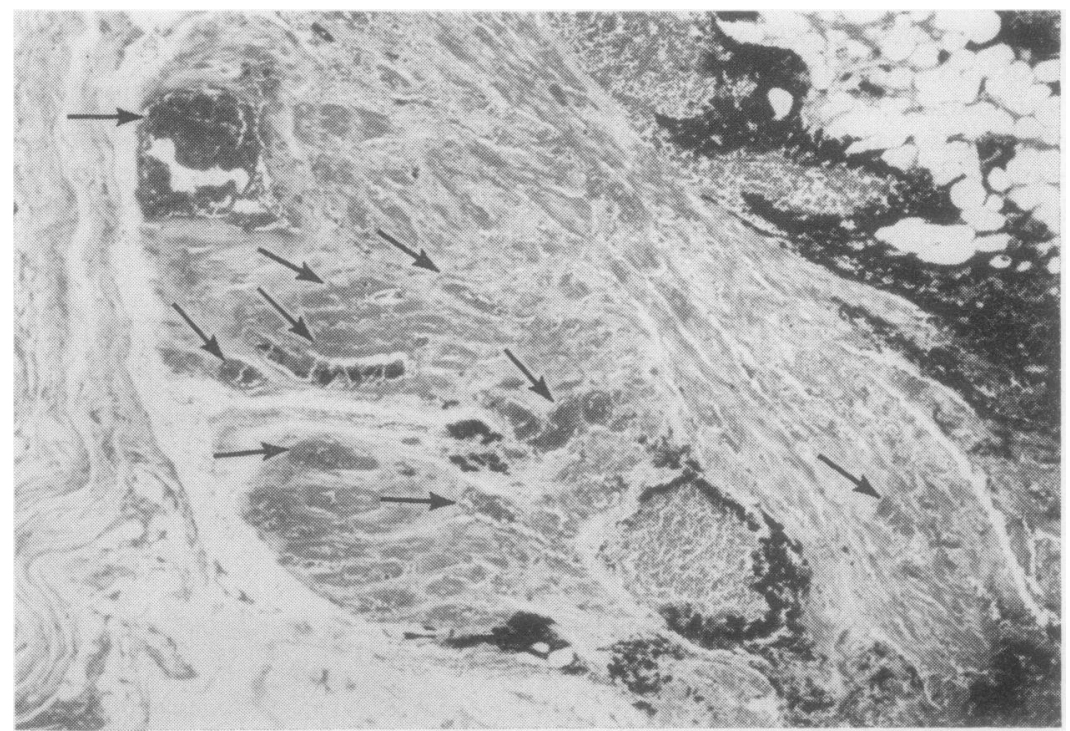

FIG. 9. Case 3. Smooth muscle bundles related to blood vessels (arrows) in capsule of anthracotic inactive hilar lymph node $(H$ and $E \times 49)$.

it quite clearly as a case of PTS and the case of Bush, McLean, and Sieker (1969) is lacking sufficient detail for inclusion. Subsequently, Wolff (1973) published important amending details to case 2 of Pachter and Lattes (1963). Including her two additional cases we have found 16 further cases in the literature. Table II divides these cases into pulmonary and non-pulmonary lymphangiomyoma groups.

Of 33 cases of PL, all have been female, and chylothorax has been reported in 26 of them as well as in five of eight patients, also female, with $\frac{0}{\sigma}$ non-pulmonary lymphangiomyomata. Therefore, our case 1 is slightly unusual in not having hado 
T A B L E I I

LYMPHANGIOMYOMA (not included in review by Miller et al (1971))

\begin{tabular}{|c|c|c|c|c|c|c|c|c|c|}
\hline \multirow[b]{2}{*}{ Author } & \multirow[b]{2}{*}{$\begin{array}{c}\text { Age } \\
\text { (year) }\end{array}$} & \multicolumn{4}{|c|}{ Clinical Features } & \multicolumn{3}{|c|}{ Sites of Lymphangiomyoma } & \multirow[b]{2}{*}{ Other Features } \\
\hline & & $\begin{array}{l}\text { Chylo- } \\
\text { thorax }\end{array}$ & $\begin{array}{c}\text { Pneumo- } \\
\text { thorax }\end{array}$ & $\begin{array}{c}\text { Haemop- } \\
\text { tysis }\end{array}$ & $\begin{array}{l}\text { Dysp- } \\
\text { noea }\end{array}$ & $\begin{array}{c}\text { Thoracic } \\
\text { Duct }\end{array}$ & $\begin{array}{l}\text { Lymph } \\
\text { Nodes }\end{array}$ & Lungs & \\
\hline $\begin{array}{l}\text { Generalized type } \\
1 \text { Fraimow and Cathcart (1962) } \\
\text { Case } 6 \\
2 \text { Justin-Besançon et al (1963) } \\
3 \text { Ardichvili et al (1970) } \\
4 \text { Pielsticker et al (1972) } \\
5 \text { Joliat et al (1973) } \\
6 \text { Luz and Hedinger (1973) } \\
7 \text { Wolff (1973) Case } 1 \\
8 \text { Lieberman and Agliozzo (1974) } \\
9 \text { Silverstein et al (1974) Case } 1 \\
10 \text { Silverstein et al (1974) Case } 2 \\
11 \text { Monteforte and Kohnen (1974) }\end{array}$ & $\begin{array}{l}27 \\
41 \\
18 \\
31 \\
65 \\
44 \\
45 \\
31 \\
26 \\
31 \\
21\end{array}$ & $\begin{array}{l}\mathbf{2} \\
\mathbf{3} \\
\mathbf{2} \\
\mathbf{3} \\
\mathbf{2}\end{array}$ & $\begin{array}{l}2 \\
1 \\
2\end{array}$ & $\begin{array}{l}1 \\
2\end{array}$ & $\begin{array}{l}1 \\
1 \\
2 \\
2 \\
1 \\
1 \\
1 \\
1 \\
1 \\
1\end{array}$ & $\begin{array}{l}\mathbf{A} \\
\mathbf{T} \\
\mathbf{T} \\
\mathbf{T} \\
\mathbf{T A}\end{array}$ & $\begin{array}{l}\mathbf{A} \\
\mathbf{A} \\
\mathbf{T A} \\
\mathbf{T} \\
\mathbf{T} \\
\mathbf{T} \mathbf{A} \\
\mathbf{T} \\
\mathbf{A} \\
\mathbf{T A} \\
\mathbf{T A}\end{array}$ & $\begin{array}{l}+ \\
+ \\
+ \\
+ \\
+ \\
+ \\
+ \\
+ \\
+\end{array}$ & $\begin{array}{l}\text { Chylous diarrhoea } \\
\text { Uterine leiomyoma. } \\
\text { Renal angioleiomyoma } \\
\text { Thrombosis of main veins } \\
\\
\text { Renal angioleiomyoma } \\
\text { Renal angioleiomyoma }\end{array}$ \\
\hline $\begin{array}{l}\text { Possible generalized type } \\
12 \text { Fardou et al (1971) } \\
13 \text { Meier-Sydow et al (1971) } \\
14 \text { Jao et al (1972) }\end{array}$ & $\begin{array}{l}35 \\
46 \\
41\end{array}$ & $\begin{array}{l}2 \\
1\end{array}$ & & 1 & $\begin{array}{l}1 \\
1 \\
1\end{array}$ & & $\underset{\mathbf{C}}{\mathbf{C}}$ & $\begin{array}{c}\text { Possible } \\
+ \\
\text { Possible }\end{array}$ & $\begin{array}{l}\text { Tuberous sclerosis } \\
\text { Oedema of leg } \\
\text { Tuberous sclerosis } \\
\text { Broad ligament leiomyoma }\end{array}$ \\
\hline $\begin{array}{l}\text { Localized type } \\
15 \text { Cavina et al (1966) } \\
16 \text { Wolff (1973) Case } 2\end{array}$ & $\begin{array}{l}36 \\
35\end{array}$ & & & & 1 & $\mathbf{A}$ & $\mathbf{A}$ & & \\
\hline
\end{tabular}

T-thoracic; A-abdominal; C-cervical; $1-4$ indicates order of onset.

a chylothorax at any time. Our case 2 is unusual in having chyloptysis though this has been reported in chylous reflux in the lungs not associated with PL or PTS (Maier, 1968) and was reported by Grewe and Beck (1952) in their case of PL (this case is the same as that reported by Brandt and Rössing (1951)).

In the 29 cases of PTS reviewed by Harris, Waltuck, and Swenson (1969), two were male and chylothorax was not mentioned. Chylothorax has, however, been reported in single cases of PTS by Wuketich (1967; case 2), Broughton (1970), and Jao, Gilbert, and Messer (1972).

Spontaneous pneumothorax occurred in 10 of the $33 \mathrm{PL}$ cases. The pneumothorax was the presenting sign in five and was associated with a chylothorax in seven patients. Spontaneous pneumothorax occurred in 14 of the 29 PTS patients reviewed by Harris et al. (1969).

Haemoptysis is occasionally encountered both in PL and in PTS. There are nine cases of PL in whom this occurred, one of whom also had tuberous sclerosis (Fardou, Dana, Fabre, Albarede, and Delaude, 1971), and three had associated renal angioleiomyomata (Vadas et al., 1967; Pielsticker et al., 1972; Monteforte and Kohnen, 1974). Harris et al. (1969) recorded haemoptysis in four of 29 cases of PTS.

RADIOLOGY Radiography in cases of PL and PTS is not diagnostic, as both are among the numerous causes of a reticular or nodular pattern.
In the early stages there is a fine granular or reticulonodular appearance. As the condition progresses a honeycomb appearance may develop and tomography will then show multiple dilated cystic spaces. Our case 1 is unusual in having a large lung air cyst. Unilateral or bilateral pleural effusions are most important features since this is rare in most other interstitial disorders of the lungs. Demonstration that the fluid is chylous is virtually pathognomonic for PL (Miller et al., 1971). The presence of thickened septal lines is also of considerable diagnostic help.

The values of lymphangiography cannot as yet be defined in helping to diagnose PL. In none of the cases in which this procedure has been carried out has the thoracic lymphangiomyomatous tissue been delineated.

In our case 1 , it seems unlikely that there was any connection between the abnormal pulmonary lymphatics and the normal lymphatic system because the patient did not have any air embolism. The large air cyst which was intubated during life was shown at necropsy to communicate with the abnormal pulmonary lymphatics. In the literature both the cases of Laipply and Sherrick (1958) and the case of Pamukcoglu (1968) also had air in their cystic lymphatics.

PHYSIOLOGY Full lung function studies are relatively scarce in the literature on PL (case VI of Fraimow and Cathcart, 1962; Justin-Besançon et al., 1963; Vadas et al., 1967; Joliat, Stalder, 
and Kapanci, 1973; Case 2 of Lieberman and Agliozzo, 1974; Silverstein et al., 1974) and PTS (Roujeau and Morel, 1961; Harris et al., 1969; Malik, Pardee, and Martin, 1970; Fardou et al., 1971).

With the exception of our case 1 and the case of Joliat et al. (1973) all published cases show a physiological pattern consistent with chronic airway obstruction or emphysema, that is, a low vital capacity (VC) with an increase in the residual volume (RV), functional residual capacity (FRC), and residual volume/total lung capacity ratio (RV/TLC). Yet the radiological pattern has been that of reticular fibrosis in the majority of cases. The paradoxical combination of a physiological pattern which is the reverse of that expected from the radiological picture may well be considered an alerting signal to look for either PL or PTS. Values for lung volumes obtained in most cases indicate clearly that pathological spaces communicate freely with airways, though the case of Joliat et al. (1973) had measurements within normal limits.

Our case 1 , however, is atypical in that the radiological picture and operative appearance were of emphysema, yet the physiological pattern was that of restriction. There was gross reduction of all static volumes (VC, TLC, RV) with normal $\mathrm{FEV}_{1}$. This paradox is partly resolved by calculating the total lung capacity from radiographs by the method of Loyd, String, and DuBois (1966). The value obtained by this method was three times that obtained by helium dilution. Therefore the communication between cysts and airways in this case was very small indeed, so that no mixing of helium into the spaces occurred during the 10 minutes allowed for equilibration. More typically, our second PL and our PTS cases showed an obstructive pattern.

In the few cases of lymphangiomyomatosis in which compliance has been measured, it has been diagnostically unhelpful (high normal-Vadas et al., 1967; reduced-Fraimow and Cathcart, 1962). Blood gases and gas exchange measurements are relatively unhelpful, the partial pressure of oxygen in arterial blood being reduced or held at normal levels by hyperventilation. Neither arterial $\mathrm{Po}_{2}$ values nor transfer factor are helpful, and the values of arterial $\mathrm{PCO}_{2}$ in the series of cases reviewed here were virtually all in the normal range. Lastly, there is no difference to be detected between the tests of lung function in PL and in PTS.

PATHOLOGY Generally the lungs in PL are described as showing multiple cysts, especially inㅡㅡㄹ the upper lobes, although in the case of Justin $\frac{\text { 을 }}{\bar{s}}$ Besançon et al. (1963) the lower lobes were more affected than the upper. The cysts are mostly lesฐ than $1 \mathrm{~cm}$ diameter but can range up to $6 \mathrm{~cm}$ as in our case 1 .

On microscopical examination of the lungs in PL the majority of reports are of smooth muscle $\vec{w}$ in lymphatics, and our cases are no except:on The lymphatics may be cystic (Delarue, Depierre $\vec{x}$ and Roujeau, 1950), dilated (Grewe and Beck $\omega$ 1952) or reduced to small clefts (Pielsticker et al.j 1972). These lymphatic abnormalities distinguishte PL from PTS. In both conditions there are alveolar or bronchiolar cysts with smooth muscle in the walls of these cysts. In PTS smooth muscle is related to blood vessels with formation of haemangioleiomyomas and, more rarely, angio $\overrightarrow{0}$ lipomyomas (Dawson, 1954; Harris et al., 1969) The presence of iron-containing macrophages in alveoli is probably more frequent in PTS than PL, which is in keeping with the abnormat haemangioleiomyomatous tissues in the former.? However, this feature is not commented on uniformly in the literature.

In our case 1 , by using large sections, we coulकूळ trace direct connections between the muscular peribronchial channels, in the characteristico position of lymphatics, with alveoli and the cysts of varying size. Unless the lungs are fixed in distension the smaller communications and the anatomical situation of the smooth muscle may, not be appreciated. Thus it is possible that in the literature some of the cysts are ectatic lymphatics. rather than cysts of the broncho-alveolar3. pathways.

The place of lung biopsy in the diagnosis ans the assessment of progress:on of PL is not yet clear and to date poses two problems. If the reported lung biopsies are arranged in order ofo time interval between biopsy and death, as in Table III, it would appear probable that theo muscle hyperplasia noted at necropsy could be an rapidly developing preterminal event. An alterna-ț tive explanation might be that in the majority of cases the biopsy has been taken from an inappropriate site. As it is the hilar lymph nodes and the peribronchial lymphatics which ares mainly involved, a superficial pleural biopsy, as in our case 1 , is unlikely to show any smooth muscleo about lymphatics. A deep wedge biopsy is mored likely to reveal the diagnosis and help to elucidate the progression of this disease.

The cases of Vadas et al. (1967), Pielstickerर et al. (1972), case 2 of Silverstein et al. (1974) and్ 
T A B L E II I

\begin{tabular}{|c|c|c|}
\hline Author & $\begin{array}{l}\text { Time Interval between } \\
\text { Biopsy and Necropsy }\end{array}$ & Lesion in Biopsy \\
\hline $\begin{array}{l}\text { Pamukcoglu (1968) } \\
\text { Cornog and Enterline (1966) Case } 3 \\
\text { Laipply and Sherrick (1958) Case } 1 \\
\text { Present Case } 1 \\
\text { Present Case } 2 \\
\text { Luz and Hedinger (1973) } \\
\text { Cornog and Enterline (1966) Case } 5 \\
\text { Monteforte and Kohnen (1974) } \\
\text { Silverstein et al (1974) Case 1 } \\
\text { Pachter and Lattes (Wolf, 1973) }\end{array}$ & $\begin{array}{l}7 \text { years } \\
5+\text { years } \\
5 \text { years } \\
5 \text { years } \\
20 \text { months } \\
20 \text { months } \\
\text { Several months } \\
\text { Approx. } 8 \text { months } \\
7 \text { months } \\
3 \text { months }\end{array}$ & $\begin{array}{l}\text { Interstitial fibrosis } \\
\text { Emphysema. Dilated lymphatics } \\
\text { Normal lung } \\
\text { Emphysema. Dilated lymphatics } \\
\text { Hypertrophic muscle fibres related to lymphatics and bronchioles } \\
\text { Consistent with lymphangiomyomatosis } \\
\text { Hypertrophic muscle fibres related to lymphatics and bronchioles } \\
\text { Lymphangiomyomatosis } \\
\text { Hypertrophic muscle in lymph node and pulmonary lymphatics } \\
\text { Hypertrophic muscle in bronchiolar cyst walls }\end{array}$ \\
\hline
\end{tabular}

of Monteforte and Kohnen (1974) require special consideration. Each had cystic lungs with muscle bundle possessing endothelial-lined clefts, some of which were blood vessels and some lymphatic. Three cases had intra-alveolar siderophages. All four cases had renal angiolipomyomata but none of the other clinical or pathological features of tuberous sclerosis. All cases had lymphangiomyomatous involvement of lymph nodes, and the case of Vadas et al. (1967) had a retroperitoneal lymphangiomyomatous tumour. We feel that these four cases on balance show more features of PL than PTS and we have, therefore, classed them as PL though Monteforte and Kohnen (1974) have argued that multiple renal angiolipomyomata are a feature of tuberous sclerosis.

The lymph nodes in PTS are usually normal but they may show lipoleiomyomatous solid nodules (Vejlens, 1941; Wilson and Lo, 1964; Rumberg and Herzog, 1966; Fardou et al., 1971). The position of the cases of Fardou et al. (1971) and Jao et al. (1972) is difficult to assess in the absence of adequate pulmonary pathology and while both had tuberous sclerosis they also both had at least one lymphangiomyomatous lymph node. The muscle in a pulmonary lymph node in our case 3 (PTS) was related to blood vessels within the node.

A more uniform picture is presented in PL by the lymph nodes and thoracic duct when involved in the lymphangiomyomatous process. These structures become a spongy mass of sinusoids with abundant smooth muscle cells in the interstitium and only a few remnants of lymphocytic foci.

Thus the composition and distribution of the lesions are different. Lymphangiomyomatosis is a condition involving lymphatics both intra- and extra-nodal in the central part of the body. Tuberous sclerosis is a mesodermal disorder affecting the body both centrally and peripherally with a special tendency to involve the smooth muscle of blood vessels.
The different nature of these two conditions is also suggested by the relative frequency of evidence of tuberous sclerosis in relatives compared with the lack of any familial incidence in lymphangiomyomatosis. Neither of our two PL cases had any family history of tuberous sclerosis or lymphangiomyomata.

Bearing in mind the differences in incidence of chylothorax, pneumothorax, family history, and the distribution and type of pathological lesions, the evidence to date suggests, therefore, that lymphangiomyomatosis and tuberous sclerosis are probably not different aspects of the same disease process but seem to be two different disorders.

Luz and Hedinger (1973) speculated in their PL case that the smooth muscle proliferation in the lungs, mediastinal lymph nodes, thoracic duct, and the lumen of veins might be a lymphatic analogue of Kaposi's haemangiosarcoma. The data on lung biopsies in PL given in Table III could support this view if sampling errors can be discounted. However, the muscle cells in PL are very regular, and mitoses have not been reported, and this taken with the exclusively female incidence makes it very unlikely. Five of the $14 \mathrm{PL}$ patients coming to laporotomy or necropsy had uterine or broad ligament fibromyomata but it is doubtful if this is significantly more than expected. There is no evidence to suggest that in these cases PL is a malignant spread from the genital tract, nor do these figures indicate any smooth muscle hyperplasia related to female sex hormone stimulation.

Of the several congenital abnormalities present in case 1 , bilateral anomalous pulmonary venous drainage does not appear in the literature on the PL syndrome. However, this venous anomaly is one of the group of cardiovascular abnormalities found in association with congenital pulmonary lymphangiectasis (Noonan, Walters and Reeves, 1970; France and Brown, 1971). The lymphatic channels in this neonatally lethal defect are 
devoid of muscle on conventional light microscopy, and involvement of non-pulmonary lymphatics has occasionally been recorded (Heumann, Korn, and Levy-Silagy, 1960; Ekelund, Palmstierna, and Östberg, 1966). There was no muscle to the dilated lymphatics in the oldest 11-year-old case of Esterly and Oppenheimer (1970). It is conceivable that, given sufficient time, muscle might develop to a degree to be recognized by conventional microscopy.

If there is a connection between PL and congenital pulmonary lymphangiectasis then the marked male predominance in the latter and the total female incidence in PL suggests that there may be an X-linked genetic component such that affected males and homozygous females are seriously affected and succumb in infancy while the heterozygous females survive to an older age to manifest the PL syndrome.

We wish to thank Dr. J. J. Daly for permission to publish details of his patient (case 2) and Drs. Warrack and Henry for permission to quote from their necropsy reports and for the loan of the histological material. We are very grateful to Mrs. P. Porter for secretarial help and to the Photographic Departments of Addenbrooke's and North Sheffield Hospitals. This work has been supported by the East Anglian Regional Health Authority.

\section{REFERENCES}

Ardichvili, D., Colard, M., and de Windt, J. (1970). Syndrome de lymphangiomyomatose. Annales d'Anatomie Pathologique (Paris), 15, 307.

Brandt, M. and Rössing, P. (1951). Über Wabenlunge und diffuse Myomatose der Lunge unter dem klinischen Bilde eines rezidivierenden Chylothorax Arztl. Wschr, 6, 902.

Broughton, R. B. K. (1970). Pulmonary tuberous sclerosis presenting with pleural effusion. British Medical Journal, $1,477$.

Bush, J. K., McLean, R. L., and Sieker, H. O. (1969). Diffuse lung disease due to lymphangiomyoma. American Journal of Medicine, 46, 645 .

Cavina, C., Marini, G., and Scarpelli, P. T. (1966). Ascite chilosa da angiopericitoma retroperitoneale (aspetti anatomoclinici e linforgrifice). Nuntius Radiologicus, 32, 181.

Cornog, J. L. and Enterline, H. T. (1966). Lymphangiomyoma, a benign lesion of chyliferous lymphatics synonymous with lymphangiopericytoma. Cancer, 19, 1909.

Dawson, J. (1954). Pulmonary tuberous sclerosis and its relationship to other forms of the disease. Quarterly Journal of Medicine, 23, 113.

Delarue, J., Depierre, R., and Roujeau, J. (1950). Lymphangiectasie pulmonaire et pneumonie chyleuse. Semaine des Hôpitaux de Paris, 26, 4906.
Ekelund, H., Palmstierna, S., and Östberg, G. (1966)음 Congenital pulmonary lymphangiectasis. Acta음 Paediatrica Scandinavica, 55, 121.

Esterly, J. R. and Oppenheimer, E. H. (1970). Lymphangiectasis and other pulmonary lesions in the asplenia syndrome. Archives ofos Pathology, 90, 553.

Fardou, H., Dana, J.-M., Fabre, J., Albarede, J.-L., and Delaude, A. (1971). Manifestations respira- $\vec{\omega}$ toires au cours d'une sclérose tubéreuse deo Bourneville associée à une lymphangiomyomatose. Poumon et Coeur, 27, 293.

Frack, M. D., Simon, L., and Dawson, B. H. (1968). . The lymphangiomyomatosis syndrome. Cancer, $22,428$.

Fraimow, W. and Cathcart, R. T. (1962). Clinical and physiological considerations in pulmonary? muscular hyperplasia. Annals of InternalMedicine, 56, 752.

France, N. E. and Brown, R. J. K. (1971). Con- $\frac{\stackrel{+}{0}}{0}$ genital pulmonary lymphangiectasis. Report of 11 examples with special reference to cardio- vascular findings. Archives of Diseases in $\vec{\bullet}$ Childhood, 46, 528.

Grewe, H. E. and Beck, E. (1952). Spätfolgen des Chylothorax und Indikation zum operativen Eingriff am Ductus thoracicus. Zentralblatt für Chirurgie, 77, 649.

Harris, J. O., Waltuck, B. L., and Swenson, E. W. (1969). The pathophysiology of the lungs in tuberous sclerosis. A case report and literature $\varrho$ review. American Review of Respiratory $\overrightarrow{\vec{O}}$ Disease, 100, 379.

Heumann, G., Korn, R., and Levy-Silagy, J. (1960). A propos d'un cas de lymphangiectasies pul-o monaires congenitales. Archives françaises de Pediatrie, 17, 1012.

Jao, J., Gilbert, S., and Messer, R. (1972). Lymphangiomyoma and tuberous sclerosis. Cancer, $\underset{\sigma}{\sigma}$ 92, 1188 .

Joliat, G., Stalder, H., and Kapanci, Y. (1973). Lymphangiomyomatosis: A clinico-anatomical entity. Cancer, 31, 455.

Justin-Besançon, L., Pequignot, H., Galey, J. J., 을 Renault, P., and Even, Ph. (1963). Lymph $\frac{D}{O}$ angiectasies pulmonaires diffuses acquises avec三. insuffisance respiratoire et chylothorax. Semaine $\mathcal{O}_{0}$ des Hôpitaux de Paris, 39, 1179.

Laipply, T. C. and Sherrick, J. C. (1958). Intrathoracic $\mathcal{O}^{\circ}$ angiomyomatous hyperplasia associated with chronic chylothorax. Laboratory Investigation,
$\mathbf{7}, 387$.

Lieberman, J. and Agliozzo, C. M. (1974). Intrapleural nitrogen mustard for treating chylous effusion of pulmonary lymphangioleiomyomatosis. Cancer, 33, 1505.

Loyd, H. M., String, S. T., and DuBois, A. B. (1966). Radiographic and plethysmographic determination of total lung capacity. Radiology, 86, 7.

Luz, A. and Hedinger, C. (1973). Lymphangiomyoma-O tose. Schweizerische Medizinische Wochenschrift, 103, 1833. 
Maier, H. C. (1968). Chylous reflux in the lungs and pleura. Thorax, 23, 281.

Malik, S. K., Pardee, N., and Martin, C. J. (1970). Involvement of the lungs in tuberous sclerosis. Chest, 58, 538.

Meier-Sydow, J., Bürger, H., Dierkesmann, R., Gebauer, A., Hügel, E., Lange, H. P., Röttger, P., and Schmidt, W. (1971). Angioleiomyomatose der Lunge. Verhandlungen der deutschen Gesellschaft für innere Medizin, 77, 1118.

Miller, W. T., Cornog, J. L., and Sullivan, M. A. (1971). Lymphangiomyomatosis. A clinicalroentgenologic-pathologic syndrome. American Journal of Roentgenology, Radium Therapy, and Nuclear Medicine, 111, 565.

Monteforte, W. J., and Kohnen, P. W. (1974). Angiomyolipomas in a case of lymphangiomyomatosis syndrome: relationships to tuberous sclerosis. Cancer, 34, 317.

Noonan, J. A., Walters, L. R., and Reeves, J. T. (1970). Congenital pulmonary lymphangiectasis. American Journal of Diseases of Children, 120, 314.

Pachter, M. R. and Lattes, R. (1963). Mesenchymal tumors of the mediastinum. III. Tumors of lymph vascular origin. Cancer, 16, 108.

Pamukcoglu, T. (1968). Lymphangiomyoma of the thoracic duct with honeycomb lungs. American Review of Respiratory Disease, 97, 295.

Pielsticker, K., Kunze, E., and Stern, G. (1972). Lymphangiomyomatose mit diffusem Befall der Lungen und multiplen Angiomyolipomen der Nieren. Beiträge zur pathologischen Anatomie und zur allgemeinen Pathologie, 147, 189.

Roujeau, J. and Morel, R. (1961). Les localisations pulmonaires de la sclérose tubéreuse de Bournville (à propos d'une observation anatomoclinique). Journal français de médicine et chirurgie thoraciques, 15, 247.

Rumberg, J. and Herzog, I. (1966). Tuberous sclerosis. New York State Journal of Medicine, $66,642$.

Silverstein, E. F., Ellis, K., Wolff, M., and Jaretzki, A. (1974). Pulmonary lymphangiomyomatosis. American Journal of Roentgenology, Radium Therapy and Nuclear Medicine, 120, 832.

Vadas, G., Pare, J. A. P., and Thurlbeck, W. M. (1967). Pulmonary and lymph node myomatosis. Review of the literature and report of a case. Canadian Medical Association Journal, 96, 420.

Vejlens, G. (1941). Specific pulmonary alterations in tuberous sclerosis. Acta Pathologica et Microbiologica Scandinavica, 18, 317.

Wilson, G. C. and Lo, D. (1964). Tuberous sclerosis: Case with pulmonary and lymph node involvement. Medical Journal of A ustralia, 2, 795.

Wolff, M. (1973). Lymphangiomyoma: clinicopathologic study and ultrastructural confirmation of its histogenesis. Cancer, 31, 988.

Wuketich, S. (1967). Angioleiomyomatose der Lunge und der Lymphknoten. Verhandlungen der deutsche Gesellschaft für Pathologie, 51, 333.

\section{ADDENDUM}

Since this paper was accepted Corrin and colleagues (1975) have reported 28 additional cases, one of which survived at least nine years after a diagnostically positive lung biopsy (cf. Table III). They also report mitoses in the smooth muscle cells in one case.

\section{REFERENCE}

Corrin, B., Liebow, A. A., and Friedman, P. J. (1975). Pulmonary lymphangiomyomatosis. A review American Journal of Pathology, 79, 348.

Requests for reprints to: Dr. P. G. I. Stovin, Papworth Hospital, Papworth Everard, Cambridge. 